MENDONÇA, Antonio g. \& Prócoro Velasques Filho - Introdução ao Protestantismo no Brasil. S. Paulo, Loyola, 1990.

MENDONÇA, Antonio. Sindicato de mágicos: pentecostalismo .e cura divina (desafio para as igrejas). In "Estudos de Religião". S. Paulo, ano VI, n ${ }^{\circ}, 1992$.

RUUTH, Anders - Iglesia pentecostal. Iglesia desafiante y desafiada. exemplar mimeografado. Chile, set. 1992.

VELAZQUEZ FILHO, Prócoro A falência do Cristianismo Tradicional e a tentativa de recu- peração proposta pelas religiões do espírito. In Fé cristã: Libertação do cativeiro do passado e a esperança . Ciências da Religião $\mathrm{n}^{0} 5$, 1986, p. 50.

WILLEMS, E. - Followers of a New Faith. Nashville, Vanderbeilt University Press, 19967.

Prof ${ }^{a}$ Yara Nogueira Monteiro, é Doutora pela Universidade de São Paulo e professora de Ciências da Religião do Instituto Metodista do Ensino Superior. End.: Rua de Olinda Rodrigues, 153 05372-100 São Paulo - SP

\title{
ABORDAGENS USUAIS NO ESTUDO DO PENTECOSTALISMO
}

Rev. Leonildo Silveira Campos

\section{INTRODUÇÃO}

Para muitos cristãos, o acercarse do pentecostalismo, talvez o fenômeno religioso mais importante deste século, é como se aproximar daquela entidade mitológica que dizia: "Decifra-me ou devoro-te". Suspeito haver pelo menos duas formas freqüentes e negativas, entre outras, de se encarar o pentecostalismo.

Uma primeira visão do pentecostalismo é resultante dos nossos temores institucionais. O pentecostalismo, nesse caso, é encarado como um "movimento-monstro", destinado a devorar todas as formas institucionais de cristianismo. Esta postura provoca nos cristãos um tremendo imobilismo, um sentimento de fracasso diante de algo percebido como ameaça.

Uma outra visão, também deformadora, é aquela que se expressa por um estado de deslumbramento diante do inusitado. Tal postura é parecida com a reação do interiorano que, postado diante do mar nunca visto anteriormente, permanece admirado. Essa postura pode evoluir para uma atitude utilitarista, quando as pessoas admiradas se aproximam do pentecostalismo, com o desejo de conhecer suas técnicas de crescimento e de aprender o seu know-how, para depois tentar aplicar tudo em sua atividade pastoral ou catequética.

Pretendemos a seguir mapear algumas das principais trilhas usadas no estudo do pentecostalismo. Julgo ser tal procedimento muito importante, principalmente para os agentes envolvidos nas várias tarefas de reprodução e expansão das formas institucionalizadas e históricas de cristianismo. Embora haja o risco do viés, é necessário aprender a decifrar os novos movimentos religiosos, entre eles o pentecostalismo, caso contrário se cumprirá a ameaça do "devoro-te".

Há também uma postura que julgamos ser mais humilde, que nasce daquele desejo de conhecer o outro e de se estabelecer um conhecimento que origine uma reavaliação das próprias posturas ritualizadas. Essa maneira de se analisar o pentecostalismo pode gerar um processo de auto-análise e até a descoberta de falhas que temos cometido no decorrer de um longo processo histórico de institucionalização.

Possivelmente um exercício de reflexão como esse possa relativizar um pouco mais as estruturas 
rígidas, as rotinas estabelecidas $\mathrm{e}$ as certezas introjetadas que temos adquirido como instituição, introduzindo dentro dela a dinâmica dos movimentos e a fertilidade da visão inovadora dos profetas.

Bonhoffer, cristão alemão que participou de um complô para eliminar Hitler, escreveu certa vez da prisão: "É preciso arriscar-se a dizer coisas contestáveis desde que se levantem questões vitais". Neste texto queremos verificar que tipo de discurso os cristãos tradicionais (católicos e protestantes), em geral participantes do "ecumenismo institucionalizado", têm articulado diante deste fenômeno, aparentemente novo, unívoco e paradoxal, que é o pentecostalismo:

1. André Droogers chama a atenção para as várias visões e epistemologias presentes nos modelos explicativos sobre o pentecostalismo, uma religião por ele considerada paradoxal. Como há diversidades de teorias e diferentes modelos de análise, o que resulta é a percepção da realidade como algo contraditória e rebelde. Que papel desempenham as ideologias dos pesquisadores na seleção das características desse fenômeno religioso e em suas respectivas explicações? O autor procura então mostrar que diante da limitação dos modelos a solução seria que os pesquisadores adotassem uma perspectiva eclética que, ao invés de excluir os atuais modelos, acabam por incorporá-los de uma forma em que eles se complementem na criação de uma espécie de realidade expressa por mosaicos. Cf. André DROOGER,Visiones paradójica. Modelo explicativos del crescimiento del pentecostalismo en Brasil y Chile, in Barbara Boudewijnse; André DROOGERS, Frnas KAMSTEEG (editores), Algo mas que opio - una lectura antropológica del pentecostalismo latinoamericano e caribeño, San Jose, Costa Rica, DEI, 1991 (pp.17-39).

2. Remeto o leitor ao provocativo texto de Wilson GOMES. Cinco teses equivocadas sobre as novas seitas populares, in Cadernos do Ceas, n.139, p. 39-53, incorporado in Alberto ANTONIAZZI e VV.AA., Nem anjos nem demônios - interpretações sociológicas do pentecostalismo, Petrópolis, Vozes, 1994.

22 REVISTADE cristianismo? Alguns séculos antes de Cristo um sábio hebreu formulou a questão: "Existe algo de novo debaixo do sol?", Esta pergunta, respondida com certo pessimismo pelo "Pregador", garantia que: "Nada existe de novo neste mundo, tudo é uma repetição do que já houve anteriormente" (Ec 1.10). É claro que uma visão limitada como essa impede o analista de vislumbrar muitas coisas novas que estão ocorrendo diante de seus olhos e acaba jogando tudo no vale comum da "mesmice". Porém, a supervalorização do novo pode criar um outro tipo de percepção inadequada quando impede a identificação dos nexos entre o presente e o passado, assim como o relacionamento dos fatos novos com outros fenômenos que o antecederam no tempo.

Além do mais, a palavra "pentecostalismo" é um cabide conceitual. Nela, muitas vezes, por causa do olhar homogeneizador, pode-se pendurar fenômenos e conceitos diferentes, de origens históricas diversas e de características contraditórias. Talvez um pouco de história nos ajude a remover parte da poeira e do cipoal, criados ao redor do pentecostalismo, desde o seu aparecimento no início do Século XX, nos Estados Unidos, até os dias de hoje.

Temos usado o termo "pentecostalismo" para aquele movimento religioso, que enfatiza em seu discurso e prática os seguintes pontos: Batismo com o Espírito Santo, a "segunda bênção" acessível ao cristão; Glossolalia (falar em línguas estranhas aos ouvintes), sinal externo do recebimento do Espírito Santo na vida; Adoção de uma ética exemplar do crente no mundo, que se expressa numa atitude de recusa das formas tradicionais de se organizar a vida na sociedade; Fervorosa atividade proselitista; Expectativa da volta imediata de Jesus a este mundo, causando o fim da história humana; Possibilidade de revelação direta de Deus ao indivíduo, através de "profecias", "sonhos" e "visões"; Ênfase no ministério da cura física e espiritual dos enfermos; Atribuição à figura de Satanás e seus demônios a causa de todos os males, havendo portanto a necessidade de exorcizá-los da vida das pessoas possuídas por eles.

Mas, seriam tais características, propriedades peculiares do pentecostalismo ou, até mesmo, do próprio cristianismo? Em que sentido elas identificam com exclusividade este movimento religioso? Essa visão retrospectiva da história do cristianismo e das demais religiões pode nos mostrar a gênese histórica de alguns elementos importantes para a compreensão do pentecostalismo como um "fenômeno moderno". Vejamos algumas delas: 
a) "Igreja Primitiva". Em várias comunidades cristãs dos dois primeiros séculos de história havia manifestações estáticas, emergência de lideranças carismáticas que fundavam em "sonhos" e "visões" a legitimidade de suas respectivas autoridades. O movimento gnóstico colocava a questão da revelação direta de Deus aos "cristãos espirituais" (de primeira linha), diferenciados dos demais, "cristãos carnais" (de segunda linha) ainda desconhecedores da verdadeira sabedoria, esotericamente conseguida. No segundo Século surgiu o movimento montanista (liderado por Montano, que por volta do ano 150 se converteu ao cristianismo, pois era um antigo sacerdote do culto pagão de Cibele), cuja base era justamente uma pregação profética, recebida diretamente de Deus por ele ou por uma das profetizas que o acompanhavam. Montano combateu arduamente o fechamento do cânon do Novo Testamento, advogava a continuidade da revelação divina através do Espírito Santo, em oposição ao processo de institucionalização da Igreja.

b) "Igreja Medieval e Moder" na". O movimento monástico também propiciou o surgimento de experiências de misticismo. É impossível ler textos de São João da Cruz, Santa Teresa de Ávila e outros místicos cristãos, sem nos lembrarmos das experiências místicas dos pentecostais e carismáti$\cos$ modernos. Joaquim de Fiori (1145-1202) chegou mesmo a preconizar que a humanidade, depois de experimentar as dispensações do Pai (lei) e do Filho (evangelho), estava naquela época iniciando a era do Espírito Santo (período de amor, alegria, liberdade e comunhão). Também, durante cinco séculos, predominou um movimento de feições carismáticas (combatido por católicos e protestantes), conhecido como "Irmandade do Livre Espírito". Esse movimento continha práticas que incluíam até mesmo a nudez ritual (como demonstração de retorno a pureza do Éden antes da queda). O rigoroso reformador protestante, João Calvino, escreveu contra um desses grupos, em 1545, um livro intitulado "Contra a seita fantástica e furiosa dos libertinos que se diziam espirituais".

c) Os grandes reavivamentos protestantes e o metodismo. $\mathrm{O}$ metodismo surgiu na Inglaterra, no Século XVIII, no bojo de um intenso movimento de reavivamento religioso, que sacudiu tanto o protestantismo na Inglaterra como o das colônias inglesas da América do Norte. Embora Wesley (fundador do metodismo), desaconselhasse a manifestação nos cultos de experiências místicas exageradas, $o$ metodismo e os movimentos de avivamento espiritual, vez ou ou- tra, eram palcos de práticas tais como, entrar em êxtase, falar línguas estranhas, queda ao chão etc. Foi porém, a ênfase na mediação emocional (aspectos abandonados pelos demais protestantes que enfatizavam somente a razão humana) como evidência da presença de Deus na vida humana, que fez do metodismo e dos avivalistas, os precursores do moderno pentecostalismo. Nos Estados Unidos o avivalismo despertou, ao lado da "religião do coração", uma religiosidade anti-intelectualista, de combate à teologia escolarizada e ao clero, denunciados como "fariseus ortodoxos" ou "letrados desprovidos de fé". O crescimento do movimento reavivacionista, em direção às regiões pioneiras (onde havia pessoas de pouca cultura escolarizada), gerava manifestações fisico-religiosas com uivos, guinchos e quedas de pessoas que se contorciam no chão. A raiz metodista iria influenciar os novos movimentos surgidos nos EUA, a partir de então, com a ênfase na santidade de vida e na busca daquela luz interior que brota da experiência imediata do indivíduo com Deus ${ }^{3}$. d) O pentecostalismo moderno. Dois pontos geográficos se tornaram importantes na origem do pentecostalismo neste Século. $O$ primeiro é a Escola Bíblica Betel (Topeka, Kansas). Seu diretor, Charles Paham, em 1901, iniciou uma série de reuniões de oração com seus alunos para buscarem a "segunda benção", isto é, o "batismo com o Espírito Santo" que, segundo ele, somente poderia ser evidenciado através do "falar em línguas estranhas". Foi assim que, nos primeiros dias de janeiro, o "fogo do Espírito caiu" sobre aquele grupo de pessoas. Os alunos passaram então a espalhar aquela novidade de vida às cidades e estados vizinhos. Em 1906, um desses alunos, negro, filho de pais que tinham sido escravos, W.J.Seymour, chegou a Los Angeles. Depois de uma primeira pregação numa Igreja dos Nazarenos, conquistou alguns adeptos e nos dias seguintes se estabeleceu num antigo templo metodista, na famosa Azusa Street, no número 312. Este endereço se tornou o segundo ponto geográfico importante da história do pentecostalismo. Pois, as experiências

3. Para uma visão um pouco mais ampla da questão das vinculações do pentecostalismo com os grandes reavivamentos espirituais e com o metodismo, cf. Donald W. DAYTON, Theological roots of pentecostalism, METUCHEN, H.J, SCARECROW Press, 1987. Sobre a questão do surgimento de uma cultura "antiintelectualista" nos EUA cf. Richard HOFSTADTER, $\mathrm{O}$ anti-intelectualismo nos Estados Unidos, Rio de Janeiro, Civilização Brasileira, 1967. 
religiosas desse local atraiam pessoas de todas as partes do país. Rapidamente as novas práticas rituais e a teologia "pentecostal" se espalharam por todo o mundo. W. H. Durhan, um pastor batista de Chicago, converteu-se ao pentecostalismo naquele lugar. Do raio de sua influência em Chicago saíram três homens que trariam o pentecostalismo para o Brasil. Em 1910 o ítalo-americano, Luigi Francescon, logo após a sua chegada no Brasil fundou, nas cidades de S.Paulo e S. Antonio da Platina, a Congregação Cristã no Brasil. No ano seguinte, os sueco-americanos, Daniel Berg e Gunner Vingren, vieram para o norte do Brasil (Belém, PA) e alí deram origem à Igreja Assembléia de Deus ${ }^{4}$.

e) Os pentecostalismos recentes. Entre 1911 e 1950 o pentecostalismo teve um crescimento vagaroso, porém irreversível em todas as regiões do país. Ainda cresciam as Igrejas do tipo "protestantismo histórico" (de missão ou de imigração). O Brasil, logo após o término da Segunda Guerra, experimentou um explosivo crescimento urbano e industrial. Rapidamente os campos se esvaziaram e as pessoas tomaram o rumo da cidade. O panorama cultural foi também se alterando. $O$ rádio e a televisão foi se tornando, cada vez mais, no interior de uma cultura ainda auditiva-oral, nos principais meios de das das pessoas reunidas em massas possibilitavam o surgimento de uma vaga pentecostal diferenciada. Surge então, resultante desse novo estado de coișas, uma acomodação pentecostal dessa sociedade urbana e industrial portadora de dramáticas carências sociais. Esse pentecostalismo passou a fazer da cura divina e da solução milagrosa dos problemas pessoais seus eixos temáticos. $E$, entre os conflitos sociais, foram se moldando novas Igrejas tais como a Igreja do Evangelho Quadrangular - Cruzada Nacional de Evangelização (1953), Cristo" (1956), Igreja de Nova Vida (1960), Igreja Pentecostal "Deus é Amor" (1961) e outras centenas de pequenas "igrejolas". $\mathrm{O}$ movimento pentecostal então se influenciar as massas. As demanIgreja Pentecostal "O Brasil para

4. Para maiores informações sobre as origens do pentecostalismo nos Estados Unidos cf. Sydney E. AHLSTROM, A religious history of the american people, New Haven, Yale University Press, 1973; Nils BLOCH-HOELL, The pentecostal movement Oslo: Scandinavian University Press, 1987; Walter HOLLENWEGER, El pentecostalismo - história e doutrinas Buenos Aires, La Aurora, 1976; Harvey COX, Fire from heaven - the rise of pentecostal spirituality and the reshaping of religion in the twenty-first century, NewYork, Addison-Wesley Publisshing Company, 1995. pulveriza numa espécie de "pentecostalismo autônomo". A estra'tégia dessas Igrejas fez do rádio um dos mais importantes instrumentos de mobilização popular e de divulgação de suas sessões de milagres. Para acomodar o povo em suas reuniões usavam, desde tendas de lona, estádios de futebol, pequenos barracos ou garagens, até enormes galpões industriais, transformados em templos, encravados nas periferias ou nas regiões decadentes da paisagem urbana das grandes cidades brasileiras. Nos anos setenta, com a população urbana ultrapassando a taxa de $70 \%$ e com a consolidação da televisão, um novo tipo, mais light de pentecostalismo, foi surgindo. Vem então à baila uma religião pentecostal de massas, que emprega com desinibição a mídia televisiva e faz dos milagres, exorcismos e promessas de prosperidade, seus principais produtos colocados, no agora competitivo mercado religioso. Desse novo patamar de acomodação surgem, a Igreja Universal do Reino de Deus, Igreja Internacional da Graça de Deus, Igreja "Renascer em Cristo", Comunidade Sara Nossa Terra etc., conjunto de movimentos e instituições renomeadas de "neopentecostais". Todos esses novos atores transitam num contexto simbólicó, saturado de influências do catolicismo popular, das religiões afro-brasileiras, do kardecismo, do protestantismo e dos próprios pentecostalismos anteriores. Estas características dariam ao pentecostalismo uma fisionomia mais "moderna" do que a do pentecostalismo "tradicional" ou "histórico", até então preso às origens dos movimentos de santidade e puritano.

De tudo o que foi afirmado acima fica então bem claro que o novo não surge no palco da história de um momento para outro. Pois, os novos movimentos religiosos assimilam e condensam tendências anteriores, interagem com as exigências concretas da sociedade e assim vão assumindo novas feições, num sucessivo e incansável processo de permanente e dialética remodelação do campo religioso.

Por isso mesmo, pode-se dizer que não há pentecostalismo no singular e que se torna impossível apresentar em algumas linhas, através de uma meia dúzia de conceitos, uma descrição profunda, correta e geral desse fenômeno tão complexo e plural. Há instituições diferenciadas, movimentos ainda não devidamente institucionalizados, teologias até conflitantes e práticas que vão, desde o culto herdeiro das tradições protestantes, estruturado ao redor das experiências avivalistas do Século XIX, até verdadeiras cerimônias e rituais mágicos, mesclados de um 
linguajar e de conceitos oriundos do kardecismo e das religiões afrobrasileiras, com alguma tonalidade de programas de auditórios, tão ao gosto do público brasileiro.

Além dessa forma histórica de se abordar o pentecostalismo, que tipo de linguagem e discursos têm sido usados para se tentar capturar nas redes conceituais um panorama tão complexo como este? É isto que se pretende analisar a seguir.

\section{O PENTECOSTALISMO NA LINGUAGEM DOS SEUS ANALISTAS}

O aparecimento de novas situações provoca, logo no seu início, uma certa confusão conceitual. Nesse momento, os paradigmas tradicionais, empregados para explicar os fenomenos mostram-se inadequados. Para usar a linguagem de Thomas Kuhn, os "paradigmas", entendidos como "modelo estabelecido por um conjunto de soluções concretas a certos problemas", empregados para se descrever e representar formalmente um objeto de estudo, não mais dão conta de certas "anomalias". Dessa desestruturação aparece então, um período de "ciência extraordinária" até que, muito depois, novos paradigmas acabam por ocupar o lugar dos antigos ${ }^{5}$.

5. T.S. Kuhn, A estrutura das revoluções cientificas, S.Paulo, Perspectiva, 1975 6. Renato Ortiz, Mundialização e cultura, S.Paulo, Brasiliense, 1994, p.14.
Com essas mudanças rompemse as lógicas, hipóteses e respostas formuladas anteriormente e divulgadas com muito sucesso. Consequentemente, estabelece-se uma confusão conceitual e lingüística $\mathrm{O}$ estudiosos desse fenômeno é de ais, lógicas e gramáticas antigas. Renato Ortiz sugeriu que, quando falamos sobre coisas desconhecidas, fenômenos em andamento e realidades fugidas, empregamos metáforas que "abundam diante da falta de conceitos" estabelecidos. Possivelmente, esta seja a causa da multiplicação de metáforas no discurso das ciências humanas atual sobre o pentecostalismo ${ }^{6}$. A transformação pela qual passa o campo religioso brasileiro nas últimas décadas, como já foi dito acima, tem sido melhor captada por tais metáforas. Elas tentam superar o caos analítico, a ambigüidade dos termos, o emaranhado de conceitos, palavras e categorias, tanto aqueles imperantes no discurso dos pentecostais, como também os empregados pelos estudiosos desse fenômeno.

Há uma necessidade de se superar definitivamente a dimensão apologética, que inicialmente toproblema que agora se coloca aos como falar de coisas novas, usando-se para isso aparatos conceitu- mou conta do discurso protestante e católico romano. Ainda hoje, em ambas as áreas, fala-se do pentecostalismo como "inimigo". Ele é a incorporação do "outro" que nega, destrói e corrompe uma "tradição pura", aquela "fé que uma vez foi dada aos santos".

Nada mais deformador da realidade a ser analisada, do que o discurso ideológico-apologético, articulado por uma instituição qualquer. É um discurso superficial, simplista e que se coloca a priori, em posição de vantagem diante do outro, que por definição é herético. Rubem Alves escreveu que situações de rupturas e de crise criam condições para o surgimento de discursos de reformulação ou de reafirmação de "programações" institucionais. É nesse clima que surge a linguagem da inquisição e do dogmatismo dos que, por pensarem que detém a verdade, estão condenados a se tornarem inquisidores?.

Para se entender bem os pentecostalismos presentes na sociedade brasileira, é preciso que seus analistas passem dos paradigmas da simplicidade para o domínio dos paradigmas da complexidade. Enquanto predominarem os paradigmas da simplicidade os fenômenos serão olhados como elementos pertencentes a

7. Rubem Alves, Dogmatismo e tolerância, S.Paulo, Paulinas, 1982 sistemas homogêneos, causados por fatores únicos (reducionismo econômico, por exemplo), portadores de uma unidade que transcende as partes, que reduz, iguala e cria um sistema intemporal e ahistórico.

Os paradigmas da complexidade, entretanto, encaram o fenômeno social, no caso o pentecostalismo, de um ponto de vista policausal, valorizam a questão do poder, das forças multiformes em luta, apontando para as condições endógenas e exógenas, que produzem no campo religioso as mutações a serem captadas através da linguagem científica e acadêmica.

Que paradigmas, segundo o nosso ponto de vista, estão perdendo a "força heurística" ou o "poder explanatório" nos vários discursos, sobre os pentecostalismos brasileiros? Que metáforas tem sido inventadas para dar conta de uma realidade que não mais cabe dentro de aparatos conceituais usados desde há décadas?

\section{PARAdIGMAS USUAIS NA} ANÁLISE DO PENTECOSTALISMO E SEUS LIMITES CONCEITUAIS

Ao discutir o aparecimento e pertinência dos esquemas conceituais e modelos explicativos, há um ponto fundamental da sociologia do 
conhecimento, que não pode ser deixado de lado. A linguagem é uma construção humana sobre a realidade, portanto mediadora. Mas, no decorrer de um processso de análise, ela corre o risco de se tornar para o analista, a própria realidade. Como tal, o discurso humano é sempre precário, limitado e destinado a superar-se a si mesmo, através de novas articulações.

$O$ discurso nasce para dar conta de situações sociais concretas e tem a intenção de intervir na realidade, isto é, de provocar mudanças. Por isso, é legítimo procurarmos identificar as forças sociais motrizes, que estão por detrás do discurso construído pelos grupos sociais, inclusive os religiosos.

Nas próximas páginas pretendemos avaliar algumas das várias portas, modelos explicativos e paradigmas, usados para se penetrar no campo religioso e no interior do fenômeno pentecostal.

\section{a) Modelos explicativos de origem geo-politica e de legitimações institucionais}

Durante as últimas décadas nos habituamos a encarar e, até a usar em nosso discurso, um grupo de explicações dualistas para os fatos sociais. De um lado estava a "ideologia da segurança nacional", esquema conceitual nascido nas escolas de guerra do Pentágono, que dividia o mundo entre "comunis- mo ateu", de um lado e, "civilização cristã e democrática", de outro. Os marxistas, por sua vez, espalhavam para todos os lados a tradicional versão de que a religião não passava de uma forma de dominação que a burguesia queria impor sobre o sofrido proletariado. Esta é a velha e surrada tese da religião como ópio e alienação.

Ambos esquemas compartilhavam de uma lógica dualista, que via no inimigo a causa de quaisquer desequilíbrios existentes em seu próprio sistema. A religião, para uns e outros, era tanto um campo como um instrumento, extremamente importantes, para se estabilizar ou desestabilizar uma determinada sociedade.

Foi neste contexto que predominou a idéia de que o protestantismo e o pentecostalismo eram fenômenos religiosos estimulados pelos interesses geo-políticos dos norte-americanos. Havia uma "invasão imperialista" na América Latina (latina e católica por definição), da qual as seitas "protestantes", "pentecostais" ou "fundamentalistas", seriam apenas a ponta de lança. Por detrás dessa invasão estaria o dinheiro dos grandes grupos econômicos e da própria CIA, interessados em barrar a penetração cubano-moscovita na América Latina.

Como subproduto dessa tese predominava, em certos setores, a idéia de que a Igreja Católica
Apostólica Romana, por causa da teologia da libertação e de seu "braço político", as Comunidades Eclesiais de Base, estaria servindo de instrumento para a entrada do comunismo neste continente. A melhor forma que os americanos teriam encontrado para barrar essa indesejável invasão, teria sido o investimento na expansão e crescimento das seitas fundamentalistas e pentecostais.

Houve, evidentemente, muita literatura produzida sobre pentecostalismo e seitas na América Latina que refletiram tais paradigmas. Parecia claro, para alguns setores católicos, de que realmente os "demônios vinham do norte". Para outros analistas, de inspiração marxista, o fenômeno pentecostalismo era mais uma forma de se procurar dominar ideologicamente o proletariado, anestesiando as suas consciências, impedindo que se aflorassem as contradições de classe e a explosão de uma revolução libertadora neste continente.

Ligado a tais premissas, surgiu também a versão de que a própria Igreja Católica, ao se "politizar excessivamente", teria "abandonado a dimensão espiritual da vida", a sua missão "exclusivamente religiosa", para se concentrar em preocupações meramente "políticas e sociais". Como resultado dessa "apostasia", as massas estariam virando as costas para a Igreja, em direção às seitas. Esta tem sido uma explicação preferida por muitas pessoas pertencentes a alas mais conservadoras da Igreja, assim como dos grandes grupos que detém o controle dos meios de comunicação de massa no Brasil (rádios, televisões, jornais e revistas).

Para muitos desses analistas, a dualidade "seita-igreja", empregada pela sociologia, desde Max Weber e Troeltsch, serviu como uma luva. Contudo, tais conceitos se tornaram armas de guerra ideológica. "Seita" se tornou uma palavra empregada para designar um grupo cismático, seccionado, que abandona a instituição religiosa legítima, para construir uma comunidade a parte, sem qualquer tradição histórica, desvinculada do tronco ligado aos apóstolos e ao próprio Jesus Cristo. "Igreja", por seu turno, é aquela instituição legítima, inserida na sociedade e portadora de um status superior ao das "seitas".

Atualmente, ambos os pólos, "seita" e "igreja", são de difícil separação. Tem razão, Júlio de Santa Ana, quando escreve que "parece-nos claro que não mais é possível afirmar que 'seita' e 'igreja' sejam realidades completamente distintas". Por exemplo, se "sei-
8. Júlio de Santa Ana, Igreja e Seita (reflexões sobre este antigo debate), in Igreja

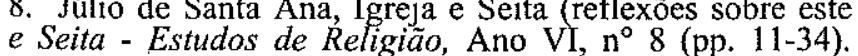


ta" tem por característica a contestação social, podemos dizer que a Igreja Universal do Reino de Deus (IURD) com a sua ênfase na inserção do indivíduo na sociedade de consumo, é uma "seita"? As várias Igrejas pentecostais brasileiras, tanto do momento de implantação (Congregação Cristã no Brasil e Assembléia de Deus), como as de momentos posteriores de expansão (Igreja do Evangelho Quadrangular, Igreja Pentecostal "O Brasil para Cristo") são "seitas"? São igrejas? São populares? Elas representam movimentos de contestação ou de acomodação social?

\section{b) Modelos explicativos oriundos da linguagem econômica}

Atreladas as teses analisadas acima, temos também um outro conjunto explicativo, que analisam as "seitas" pentecostais como meras "agências" prestadoras de serviços espirituais. Esse discurso, empregando a lógica capitalista, mostra que em nossa economia tudo se transforma em valores de troca. Isto é, os próprios produtos religiosos podem ser vendidos e

9. Há um texto escrito sobre este assunto nos anos 70, apresentado por Duglas 9. Haira Monteiro (Igrejas, Seitas e Agências: Aspectos de um ecumenismo popular) Teixeira Monteiro (Igrejas, Seitas e Agencias: Aspectos de um retigioso?) Cf. Edenio Valle e José J.Queiroz (org.) A cultura do povo, S.Paulo, Cortez \& Moraes/Educ, 1979. 10. Revista $\left.I_{\text {sto }} \dot{e}, \mathrm{n}^{\circ} 1321-25 / 1 / 95, \mathrm{p} .5\right)$. comprados, como quaisquer outros produtos. Neste caso, as igrejas pentecostais se aproximam do modelo "empresa" e tem por objetivo, como outras organizações, maximizar seus lucros, aumentar a participação no mercado, estabelecer estratégias de marketing e levar os seus agentes pastorais a se tornarem cada vez mais produtivos".

Para o Rev. Caio Fábio Jr, da sileira), o líder da IURD, Edir Macedo, "é uma águia" que "montou uma igreja baseada no sincretismo..." (....) é um saqueamento psicológico e espiritual feito ao bolso das pessoas"10. Esta tem sido a linha de argumentação de todas as matérias publicadas na imprensa brasileira e na mídia eletrônica. É claro que tais críticos procuram separar o "bom" do "mau" pentecostalismo, as "seitas" inofensivas das perigosas. Para a imprensa brasileira, certas "seitas pentecostais", são casos de polícia, pois não passam de "arapucas" para arrancar dinheiro de uma população "pobre e sofrida".

A linguagem econômica tem também sido usada para explicar o funcionamento do "mercado dos AEB (Associação Evangélica Bra- bens simbólicos". Reunindo conceitos oriundos de Max Weber, Peter Berger e Pierre Bourdieu, os que articulam este discurso procuram classificar os agentes religiosos a partir da noção de "produtores" (clero) e "consumidores" (laicato) de bens simbólicos. Neste discurso, o "campo religioso" se identifica com o "mercado". Nele operam as leis próprias de uma economia, onde a circulação de bens, obedece as configurações objetivas de poder acumulado pelos agentes, em constante luta pelo monopólio da produção e da circulação desses bens.

\section{d) Modelos explicativos sociológicos}

Desde os anos 60 tem se procurado relacionar a expansão pentecostal com as principais mudanças estruturais da sociedade brasileira e latino-americana. Assim tem sido enfatizado a decomposição do mundo rural, a crise do sistema oligárquico tradicional, a transferência maciça de camponeses para as cidades.

No corpo explicativo empregavam-se os conceitos "anomia" (Durkheim), "alienação" (Marx) e "racionalização modernizadora" (Weber) para se explicar as novas preferências religiosas das classes populares. Esses novos movimentos religiosos, especialmente os pentecostais, eram inseridos num quadro em que a religião tinha por função inserir e integrar essas camadas da população no contexto de uma sociedade em processo crescente de urbanização e industrialização.

Outras discussões sociológicas procuraram enfatizar a questão da continuidade ou da ruptura do pentecostalismo com o universo simbólico rural. Uma das questões mais freqüentes, oriundas dessa perspectiva, se referia ao pentecostalismo como recusa à cultura mágica, camponesa e indígena deste continente. Perguntava-se então: Seria realmente recusa ou apenas mais uma forma de adaptação da religiosidade pentecostal a um novo contexto de inserção numa cultura de mercado mundial? Por exemplo, C.Lalive D'Epinay, nos anos 60 , analisou o pentecostalismo (chileno e brasileiro) a partir da reconstrução do mundo rural dentro de uma nova conformação urbana.

Tem-se buscado também relacionar o fenômeno religioso $\mathrm{e}$ as mudanças no campo religioso brasileiro com a estratificação social do país. Desde as primeiras publicações de Rolim, alguns estudiosos têm analisado o pentecostalismo a partir da questão da pobreza. Outros têm procurado mostrar que o surgimento e expansão do neopentecostalismo tem algo a ver com as exigências e valores da classe média urbana 
e) Modelos explicativos que privilegiam aspectos culturais

Analistas, com tradição antropológica, têm procurado ligar o pentecostalismo ao embate entre culturas, que atuam no processo de criação de identidades, no interior de uma sociedade em processo de complexização. A "religião popular" (categoria na qual o pentecostalismo é incluído) no Brasil possui, dentro dessa visão, alguns eixos definidores que emergem de uma matriz instalada no imaginário social ${ }^{11}$. Na constituição dessa matriz teriam participado, com força e presença desigual, o catolicismo popular português, as religiões de origem africana, o kardecismo, o animismo indigena e também, muito recentemente, o próprio protestantismo.

Como resultado dessa matriz temos: A crença em espíritos que se manifestam através do ser humano, a aceitação com naturalidade da presença de forças demoníacas entre as pessoas, a expectativa de que alguém ou alguma entidade se apresentará para de um só golpe redimir toda a sociedade (messianismo). Essa matriz tem

11. Cf. as análises da antropologia cultural de Gilberto Velho, Projeto e metamorfose - antropologia das sociedades complexas, Rio de Janeiro, Jorge Zahar Editor, 1994.

12. Pierre Sanchis, Pra não dizer que não falei de sincretismo; in Comunicaçôes do Iser, $\mathrm{n}^{\circ}$ 45, 1994, ( pp 4-11). Cf. também Erwino Schmidh e Walter Altmann (ed.) Inculturação e sincretismo, S.Leopoldo, Porto Alegre/ Conic-IEPG, 1995.

34 REVISTAde provocado o aparecimento de uma visão de mundo persistente em sua homogeneidade, fenômeno conhecido pela palavra "sincretismo".

Pierre Sanchis, na tradição de Roger Bastide e Cândido Procópio Ferreira Camargo, tem insistido na questão do sincretismo resultante da fusão, justaposição ou interpenetração dessas várias culturas ${ }^{12}$. Este ponto de vista valoriza no pentecostalismo aqueles traços que o aproxima das demais forças culturais que constituem o perfil da cultura brasileira. Alguns têm trafenômeno da globalização, analisando a redescoberta do sagrado, num contexto de transformação do mundo todo numa cultura interdependente. Que ligação teria então da modernidade e o aparecimento da pós-modernidade?

\section{f) Modelos explicativos pastorais}

Este conjunto de explicações tem uma preferência especial por parte dos agentes pastorais $\mathrm{e}$ visam legitimar as diversas formas de intervenção na realidade. Eles balhado esta questão a partir do o pentecostalismo com o colapso procuram apresentar o pentecostalismo como resultante da "sede de Deus", da "carência espiritual" das massas, do "colapso do processo de modernidade" e do fim do paradigma da secularização. É a revanche do sagrado que, impulsionado por essa sede, recusa os canais entre o sagrado e o profano construído pelas instituições tradicionais. Nesse caso, o fenômeno religioso é algo que não mais cabe dentro das agências religiosas e nem tampouco nos limites da própria religiosidade, tal como sempre foi delimitada.

O pentecostalismo seria, portanto, uma reação ao secularismo da sociedade moderna, uma recusa de um estilo de vida que teria eliminado a espiritualidade de seu centro. As Igrejas, denominações e instituições tradicionais teriam se esquecido das necessidades das pessoas, em especial das camadas pobres da sociedade. Por outro lado, a falta de padres, pastores e catequistas, teria criado um vazio, agora preenchido por novos movimentos religiosos. Tudo isso teria se agravado por uma catequese deficiente, pela existência de uma liturgia muito formal e pela suposição de que todos os brasileiros já eram cristãos e que seriam então desnecessárias quaisquer tentativas de evangelização.

Ressalta-se também", nessa linha explicativa, a passagem da "modernidade" para a "pós-moder- nidade", o que estaria provocando o aparecimento de novas demandas religiosas, exigindo-se do corpo sacerdotal e profético das Igrejas e denominações, uma rearticulação interna do discurso, práticas e rituais, para se adequar a um novo contexto cultural.

\section{Conclusão}

Ao se tentar analisar o pentecostalismo não se pode, portanto, deixar de lado a inflação de métodos, paradigmas, conceitos e metáforas ora existentes. Vivemos uma crise de linguagem, uma fragmentação do discurso sobre os fenômenos religiosos de um modo geral. Mais do que nunca é preciso perguntar sobre quem está dizendo o que, a partir de onde, sobre o pentecostalismo. E, muito mais do que isso, é preciso perguntar sobre que tipo de pentecostalismo está se falando.

Não se trata então de uma mero esforço retórico, mas sim, até uma questão de respeito para com um objeto de estudo, que recusa as camisas de forças históricas e doutrinárias e espera uma linguagem no mínimo honesta. Está na hora de se deixar de falar tantas coisas equivocadas a respeito do fenômeno pentecostal e carismático. Somente assim novos paradigmas surgirão, dando outros rumos para o discurso e investigações sobre os pentecostalismos. 


\section{PEDRO CARLOS CIPOLIN}

\section{SACRAMENTO DE SALVAÇÃO INTEGRAL} A TEOLOGIA dA IGREJA dos POBRES NA AMÉRICA LATINA

(Tese de Doutorado em Teologia)

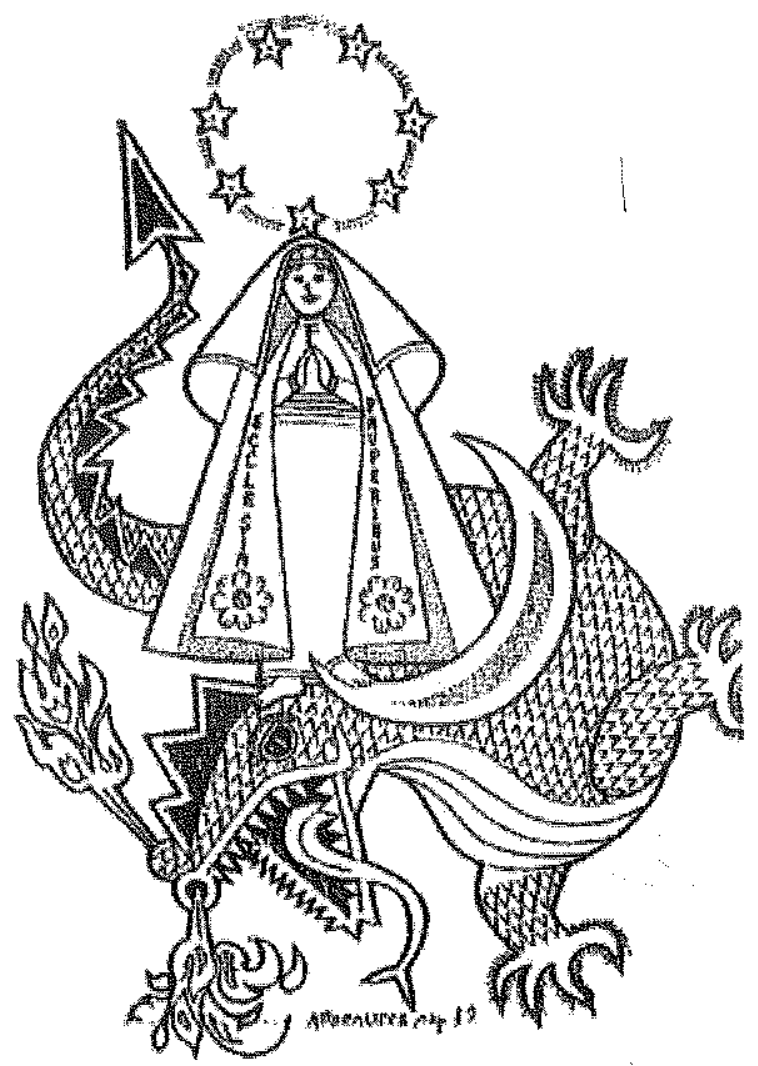

A tese estuda a eclesiologia da América Latina na década de oitenta, tomando A tese da questão da "verdadeira lgreja e suas notas", estabelecendo previamente a da questão da "verdadeira Igreja e suas notas", estabelecendo previa notarun" perspectiva dominante da apologética pré-conciliar e a evolução da "via notarun" na doutrina eclesiológica do Vaticano II, o concílio "eclesiológico" por excetência.

\section{PERSPECTIVAS SOCIOLÓGICAS SOBRE O PENTECOSTALISMO $\mathbb{E} O$ NEOPENTECOSTALISMO}

Prof $^{a}$ Cecilia Loreto Mariz

O objetivo deste artigo é identificar de forma crítica as principais questões sociológicas levantadas nos estudos sobre o pentecostalismo no Brasil . Não pretendo aqui fazer uma revisão extensa dà literatura sobre o tema. Vou me concentrar, em especial, às críticas feitas ao neopentecostalismo que é $o$ tema mais em voga nos trabalhos mais recentes ${ }^{1}$.

Ao analisar a literatura sócioantropólogica sobre o crescimento do pentecostalismo no Brasil e na América Latina observamos que esta retoma as questões centrais dos clássicos da sociologia: a anomia que preocupava Durkheim, a alienação de classe problematizada por Marx, e a racionalização moderna discutida por Weber. Os trabalhos pioneiros da década de 60 como o de Enílio Willems (1967), o de Christian Lalive D'Epinay (1967) e o de Beatriz Muniz de Souza (1967) destacam o papel do pentecostalismo como um instrumento de integração social do indivíduo em uma sociedade urbana

1. O presente artigo é uma versão revista do artigo "El debate en torno del pentecostalismo autónomo en Brasil"publicado na revista argentina Sociedad y Religión 13: 21-32. março 1995. em intenso processo de transformação. Mas não é apenas o problema durkheiminiano da anomia moderna que aparece nos trabalhos desses autores. Enquanto Willems, com inspiração weberiana, aponta para alguns elementos do pentecostalismo que rompem com a tradição, Lalive D'Epinay chama atenção para a continuidade do padrão pentecostal com o tradicional e defende que esta religião reforça o "status quo" e que seria então alienadora. Assim, por uma lado há um acordo quanto ao papel do pentecostalismo como protetor contra a anomia, por outro há uma discordância quanto ao potencial transformador do pentecostalismo. Há uma concordância que esta é uma religião do pobre e do oprimido em geral, mas discorda-se se ela ajuda a transformar a vida do oprimido ou se reforça esta sua opressão. As duas interpretações distintas das consequências do pentecostalismo ganham defensores nos trabalhos que apareceram nas décadas seguintes. Estas posições apa- 